\title{
La "Conquista Espiritual del Reino de Chile": 'capas' de una crónica jesuita del siglo XVII
}

\author{
The "Conquista Espritual del Reino de Chile": \\ layers of a XVII century Jesuit chronicle
}

\author{
MANUEL CONTRERAS SEITZ \\ Instituto de Lingüística y Literatura, Universidad Austral de Chile \\ Correo electrónico: manuelcontreras@uach.cl
}

\begin{abstract}
Resumen
El jesuita Diego de Rosales es conocido por su Historia General del Reino de Chile, donde da a conocer la naturaleza física de la región, así como la vida y costumbres del pueblo mapuche. Sin embargo, su otro escrito de importancia, la Conquista Espiritual del Reino de Chile, prácticamente ha permanecido inédito, aún tratándose de una obra de envergadura - consta de 429 folios a doble columna - donde se da a conocer no sólo la vida y obra de los padres de la Compañía que realizaron tareas apostólicas en Chile, sino importantes formas de vida cotidiana y trabajo permanente con los indígenas del sur de la región, que vienen a contrastar con el imaginario colectivo sobre el desempeño hispano en la zona. En este artículo, daremos cuenta del contacto sociocultural y lingüístico que Diego de Rosales transmite, directa o indirectamente, a través de este menologio jesuita.
\end{abstract}

Palabras clave: Conquista espiritual - Chile colonial-Edición de documentos coloniales

\begin{abstract}
The Jesuit Diego de Rosales is known for his General History of the Kingdom of Chile, which discloses the physical nature of the region and the life and customs of the Mapuche people. However, his other writing of importance, the Spiritual Conquest of the Kingdom of Chile, has virtually remained unpublished, although it concerns a major work -consisting of 429 folios in two columns- that discloses not only the life and work of the priests of the Society, who performed apostolic tasks in Chile, but important forms of everyday life and permanent work with indigenous people of southern region, which contrasts with the collective imaginary concerning the Spanish performance in the area. In this paper, we will take account of the sociocultural and linguistic contact that Diego de Rosales transmitted, directly or indirectly, through this Jesuit menology.
\end{abstract}

Keywords: Spiritual Conquest - Chilean colonial period - Editing colonial documents. 


\section{INTRODUCCIÓN}

La obra del jesuita Diego de Rosales es principalmente reconocida por su Flandes Indiano Historia General del Reino de Chile, en el cual efectúa una descripción física de la tierra, las costumbres de sus gentes (principalmente las de los mapuche), la historia del Reino, desde el descubrimiento de Almagro hasta la rebelión indígena de 1655. Con todo, si bien sabemos que existe otra obra -la Conquista Espiritual-, ésta ha pasado casi inadvertida, salvo por la publicación del Libro IV, en la obra de Valdés Bunster, Seis misioneros en la frontera mapuche.

El manuscrito, que se encuentra en la Biblioteca Nacional de Chile (Biblioteca Americana "José Toribio Medina") consta de 428 folios a doble columna, faltando parte del manuscrito, como se describe en el folio 429, agregándose de una mano distinta alguna información complementaria. Este texto, una verdadera crónica de esta Viceprovincia de la Compañía de Jesús, se centra en la vida de los misioneros y sus más destacadas acciones. Aun cuando algo diverso de lo que podemos encontrar en México o Perú, esta se enmarca dentro de una tradición escrituraria particular, destinada a servir de guía y modelo al hombre común, junto con constituirse en una forma de resaltar las virtudes de los miembros de una Orden específica, narrando sus venturas y desventuras, con la finalidad de 'certificar' la santidad de sus miembros y, por ende, la grandeza de la misma Orden.

En el caso, por ejemplo, de la América colonial, se apeló a la vida de ciudadanos tanto clericales como seculares para que fuesen una guía de comportamiento. Algunos individuos se destacaron dentro de la sociedad novohispana por reunir méritos excepcionales, por lo que fueron elevados a la categoría de virtuosos, modelos de vida y virtud cristianas. En algunas ocasiones estos individuos presentaban incluso rasgos prodigiosos, lo que alimentó una fama de santidad mediante la atribución de milagros. Sus exequias se transformaron, entonces, en escuelas dominicales donde los sermones fúnebres que se daban fueron discursos normativos a partir de la ejemplaridad. Estos textos poseían una profunda carga semántica en torno a la purificación de las almas y el control de las pasiones.

Ahora bien, no sólo los sermones fueron un receptáculo para la fama de santidad novohispana. Se utilizó, también, el recurso formal del menologio, lo que permitió hacer un catálogo de vidas ejemplares mediante relatos cortos dispuestos por día y mes. Estos minicuentos tienen su unidad temática en el sujeto, del cual se narran sus aventuras y desventuras. Tanto los jesuitas como los franciscanos redactaron sus menologios; los primeros incluyeron a padres y hermanos, mientras que los segundos incorporaron a las Clarisas. Más allá de la exageración propia que este tipo de textos requerían, relacionada con la certificación de una santidad y un panegírico tanto del sujeto como de la orden respectiva, estos escritos nos permiten hoy en día tener noticias sobre quiénes componían las instituciones religiosas durante los siglos XVI y XVII: fecha y lugar de nacimiento, cómo llegaron al Nuevo Mundo, sus principales misiones, de qué murieron y en qué fecha.

Lo que aquí trataré de abordar es el carácter de la edición de este manuscrito, a partir de la concepción de Casassas (2011) de una edición en capas, quien propone, a partir 
del trabajo con textos romances aljamiado-árabes, cuatro niveles de análisis: reproducción digital del manuscrito, edición del texto del manuscrito en su grafía (árabe) original, transliteración / transcripción y versión modernizada del texto, dirigida a un público amplio.

\section{La Conquista TeXTUAL DE UN TRabajo espiritual}

En el trabajo con la Conquista Espiritual se ha seguido un proceso similar, con adaptaciones, y que también se ha reestructurado en su concepción, a partir de tres conceptos básicos, derivados de los coserianos estructura, arquitectura e historia (en nuestro caso, memoria).

En el nivel de la estructura tendremos cuatro capas, que dicen relación con la descripción funcional del manuscrito en sus aspectos de reproducción, codicológicos y paleográficos:

2.1) reproducción digital completa del manuscrito original: se recomienda digitalizar cada folio de manera independiente, con el fin de trabajar en una reproducción de buena calidad, ojalá limpia de los posibles defectos, inclusive del manuscrito mismo, por medio de un procesamiento informático adecuado, como en el ejemplo que se ve a continuación, correspondiente a la primera foja del documento, siendo la primera imagen una versión escaneada del original, mientras que la segunda ha sido tratada con ArcPhoto Studio, mediante diversos filtros de corrección de imagen.
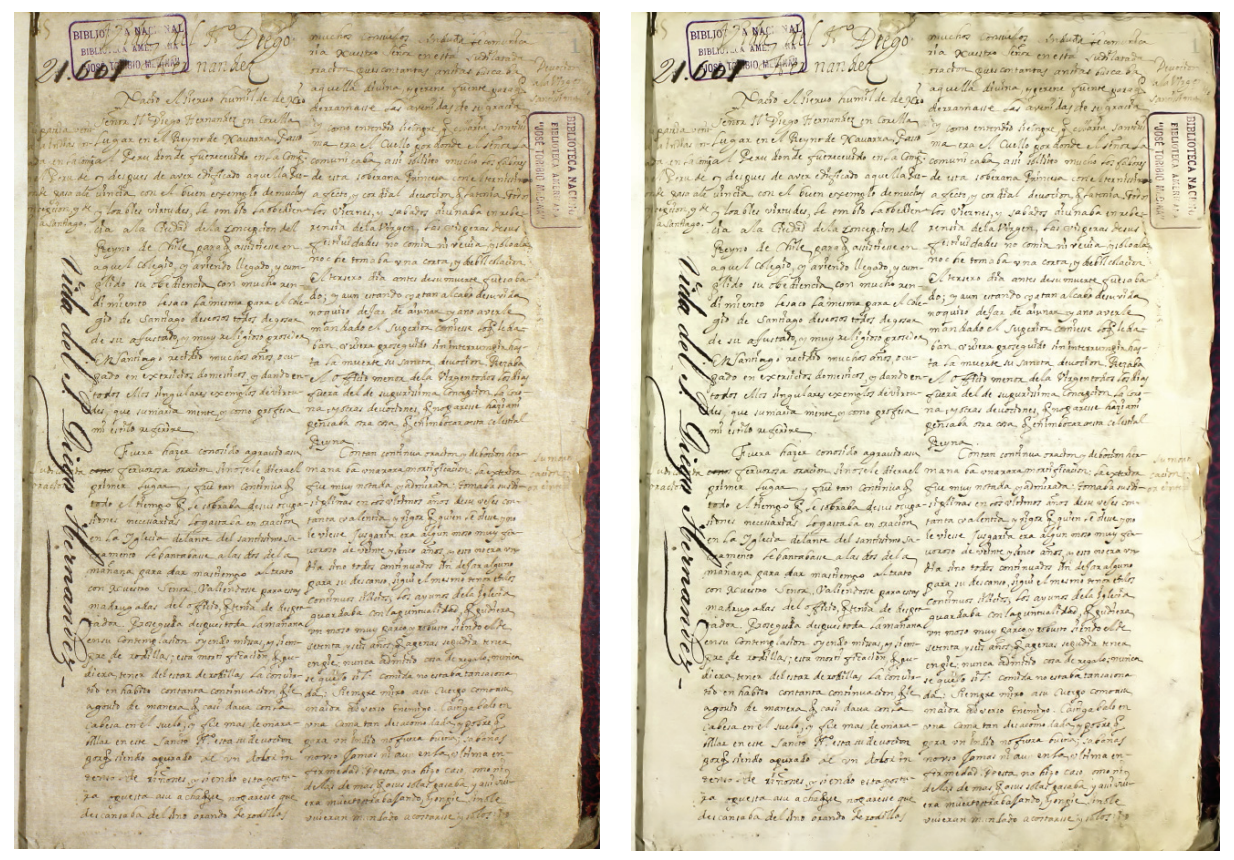
2.2) edición paleográfica del texto: tal como aparece en el manuscrito, sin enmendar ni corregir los posibles errores o descuidos del autor o copista. Considero que ésta debe ser la base para todas las demás, y particularmente en aquellos manuscritos de difícil lectura. Aquí estaría la edición propia del manuscrito ("lecturas dudosas, refrencias a posibles errores del autor o copista, particularidades del texto en el manuscrito difíciles de reproducir fielmente en la edición, etc...”). Siguiendo con el mismo texto anterior, presento parte de la edición paleográfica, de la primera columna del folio 1:

Vída del Ho Diégo / Hernandez / Nacío el síeruo humílde de Nro / Señor Ho Díego Hernandez en Corella / lugar en el Reyno de Nauarra Paso / al Peru donde fuereceuído en la Compa . / despues de aver edífícado aquella Pro- / uíncía, con el buen exemplo de muchas / y loables vírtudes, se embio la obedien- / cía a la Cíudad de la concepcíon del / Reyno de Chíle, para $\$ assístíesse en / aquel colegío, y avíendo llegado, y cum- / plído su obedíencía, con mucho ren- / dímíento le saco la mesma para el cole- / gío de Santíago deseosos todos de gosar / de su aJustado, y muy relígíoso proseder / En Santíago recídío muchos años, ocu- / pado en exersícíos domestícos, y dando en- / todos ellos síngulares exemplos de vírtu- / des, que sumaría mente y como profesa / mí estílo referíre.

2.3) transliteración: "tiene como fin la sustitución de las unidades gráficas de un texto /.../ con las unidades de otro sistema gráfico /.../ según un criterio preestablecido de equivalencias biunívocas, y sin que sea integrado ningún elemento que no se encuentre presente en el texto original". Entonces, lo que se pretende con esta herramienta metodológica es dar cuenta del contenido exacto del texto para todos aquellos que no cuenten con las competencias necesarias para realizar una lectura adecuada de las grafías del mismo, a fin "de posibilitar la reconstrucción del texto original de manera unívoca". Por ejemplo, en

el caso de la abreviatura ${ }_{2}$ efectuamos el reemplazo por la equivalente en el juego de caracteres ALPHABETUM Unicode ' $\square$ ' o, en el caso del despliegue de la misma, por 'que', de acuerdo con los criterios paleográficos vigentes.

2.4) transcripción: se refiere "al empleo de un conjunto de signos para representar simbólica o gráficamente los sonidos o fonemas de una lengua sin tener en cuenta las letras o signos ortográficos que se emplean en la escritura ordinaria. En las transcripciones normalmente no existe, ni se pretende, una relación unívoca entre el original y el texto transcrito". En el caso siguiente, correspondiente a un texto con grafía procesal encadenada del siglo XVI - para poder ejemplificar más claramente - tenemos la palabra 'sesenta' sengonan época, pero que no se corresponde con alguno de los valores conocidos en la actualidad. 
Diversos criterios de transliteración y transcripción han sido acordados, precisamente, a partir de diversas reuniones de proyectos de ALFAL, los que dieron origen a colecciones como los Documentos para la Historia Lingüistica de Hispanoamérica. Siglos XVI a XVIII (1993, 2000 y 2008). En los casos de Company (1994), Contreras (2005, 2013), Contreras et al. (2013), Rivarola (2009) y Melis et al. (2008), entre otros, se efectúa una edición semidiplomática, desplegándose las abreviaturas, lo que se indica en cursiva, como puede apreciarse en las columnas siguientes:

\begin{tabular}{|c|c|}
\hline Transcripción paleográfica & Transcripción semidiplomática \\
\hline $\begin{array}{l}\text { Vída del Ho Diégo / Hernandez / Nacío el síeruo } \\
\text { humílde de Nro / Señor Ho Díego Hernandez en } \\
\text { Corella / lugar en el Reyno de Nauarra Paso / al } \\
\text { Peru donde fuereceuído en la Compa / despues de } \\
\text { aver edífícado aquella Pro- / uíncía, con el buen } \\
\text { exemplo de muchas / y loables vírtudes, se embio } \\
\text { la obedien- / cía a la Cíudad de la concepcíon del } \\
\text { / Reyno de Chíle, para \ assístíesse en / aquel cole- } \\
\text { gío, y avíendo llegado, y cum- / plído su obedíen- } \\
\text { cía, con mucho ren- / dímíento le saco la mesma } \\
\text { para el cole- / gío de Santíago deseosos todos de } \\
\text { gosar / de su aJustado, y muy relígíoso proseder / } \\
\text { En Santíago recídío muchos ańos, ocu- / pado en } \\
\text { exersícíos domestícos, y dando en- / todos ellos sín- } \\
\text { gulares exemplos de vírtu- / des, que sumaría men- } \\
\text { te y como profesa / mí estílo referíre. }\end{array}$ & $\begin{array}{l}\text { Vida del Hermano Diégo / Hernandez / Nacio el } \\
\text { sieruo humilde de Nuestro / Señor Hermano Diego } \\
\text { Hernandez en Corella / lugar en el Reyno de Nauarra } \\
\text { Paso / al Peru donde fue receuido en la Compañía / } \\
\text { despues de aver edificado aquella Pro- / uincia, con el } \\
\text { buen exemplo de muchas / y loables virtudes, se em- } \\
\text { bio la obedien- / cia a la Ciudad de la concepcion del } \\
\text { / Reyno de Chile, para que assistiesse en / aquel cole- } \\
\text { gio, y aviendo llegado, y cum- / plido su obediencia, } \\
\text { con mucho ren- / dimiento le saco la mesma para el } \\
\text { cole- / gio de Santiago deseosos todos de gosar / de su } \\
\text { ajustado, y muy religioso proseder / En Santiago reci- } \\
\text { dio muchos años, ocu- / pado en exersicios domesti- } \\
\text { cos, y dando en- / todos ellos singulares exemplos de } \\
\text { virtu- / des, que sumariamente y como profesa / mi } \\
\text { estilo referire. }\end{array}$ \\
\hline
\end{tabular}

En cuanto a la arquitectura, constituida por las diferencias que se dan en los distintos planos, esta fase del análisis contempla dos niveles:

2.5) lengua original / lengua meta: Casassas (2011) propone que se pueda localizar la obra original. En nuestro caso, por ser un texto cuya lengua de partida y de llegada es la misma, esta sección pudiera no ser pertinente, salvo que se encontrasen textos o partes de ellos en una lengua distinta - latín o mapudungun - y que pudiese, en esos casos, rastrearse la referencia original que muchas veces queda en etapa de interlengua, sobre todo en los textos jurídicos coloniales chilenos. En todo caso, no es que el texto de la Conquista se encuentre exento de estos casos, muy por el contrario, entre otros podemos leer: "Pudosse de- / cír muy bíen del $\mathrm{H}^{\circ}$ Díego Hernandez tanque / apis argumentosa deseruist". Esta indicación inicial del manuscrito parece estar referida al canto Domine Jesu Christe, compuesto por Jean Maillard en 1559, para ser interpretado a capella por cuatro voces, como sexto responsorio de los maitines de Santa Cecilia, y que en su texto latino dice: 
Domine Jesu Christe, pastor bone, seminator casti consilii, suscipe seminum fructus quos in Caecilia seminasti:

Caecilia famula tua quasi apis tibi argumentosa deservit.

Nam sponsum, quem quasi leonem ferocem accepit,

ad te quasi agnum mansuetissimum destinavit.

Caecilia famula tua quasi apis tibi argumentosa deservit.

2.6) edición crítica: siguiendo a Kordić (2010:285), se entiende "como sinónimo de texto filológicamente procesado, editado con criterios rigurosos y científicos acorde a la realidad y las necesidades de la producción local". En todo caso, no podría faltar un estudio de contenido, que permita situar la comprensión del texto en el marco global de la cultura y sociedad de la época en la que se ha producido; imprescindible, también, resulta la elaboración, al menos, de un glosario del léxico del manuscrito que no sea el habitual en la variante lingüística meta, considerando la factibilidad de acompañar el lexema en la grafía original y, en lo posible, con sus respectivas alografías.

Los estudios lingüisticos propiamente tal son inherentes a una labor como ésta; entre otras cosas, son un aporte fundamental a la hora de distinguir los manuscritos de acuerdo al desarrollo histórico de la lengua de acuerdo a las diversas zonas geográficas, épocas o estilos, así como el generar información para la datación de los textos y manuscritos. En el caso que lo amerite, como lo es el de nuestro manuscrito de la Conquista Espiritual del Reino de Chile, es también pertinente un estudio literario, dado que los menologios-campo en el que situamos esta obra- estarían posicionados en el marco de los géneros referenciales (al que pertenecen, también, las hagiografías como campo genérico).

La tradición flológica chilena, en todo caso, se ha consolidado a través de una labor de décadas, por medio de las ediciones de la Biblioteca Antigua Chilena, elaboradas por Mario Ferreccio y Raïssa Kordić, dejando constancia de las normas textológicas utilizadas en el Purén Indómito, primer manuscrito dado a la luz por esta colección y que están muy bien sintetizados en Kordić (2005:27-28)

La reducción fonografemática realizada contempla el principio básico del respeto y conservación de todo rasgo gráfico que implique efectiva o eventualmente la representación de un rasgo fónico diferencial, significativo; todo aquel recurso que, tras el examen del comportamiento gráfico del escriba, demuestre ser inoperante, se moderniza, con el fin de evitar en el texto editado la presencia de inútiles grafías exóticas que sobrecarguen visualmente el texto y confundan al lector.

Se simplifican las letras geminadas cuyo valor sea idéntico al de sus simples: abrill > abril; ffresadas > fresadas; missas > misas; rrelijiosos > religiosos.

Se actualizan los siguientes usos gráficos: quales > cuales; Christo > Cristo; cathedral > catedral; Joseph > Josef; forçosa > forzosa; obligaçion > obligación; ziudad > ciudad; oxo > ojo; lijitimas > ligitimas; muger > mujer; bestido > vestido; auer > haber; hultima > última.

Las nasales también se representan según el uso actual: enpezar > empezar; emferma $>$ enferma. Las tildes o signos suprasegmentales de nasal se transcriben como $n$ : $\bar{e}(\dot{e})$ tierro > 
entierro; en caso de omisión de la misma, si la voz no se presta a confusión, se restituye sin comentario: acompanen > acompañen; se restituye la vocal protética en caso de presencia de $s$ en posición implosiva inicial: scribano > escribano.

Se conservan, sin indicación alguna, las contracciones habituales de la época como deste, della, etc.; las contracciones circunstanciales se indican con un apóstrofo en el lugar correspondiente: qu'es, qu'está, etc.

Se conservan tales cuales los latinismos hispanizados o vulgarizados: u supra, partesnostes, proter numsias, etc.

Se aplican, en la medida en que la confusa sintaxis lo permite, las normas actuales de puntuación, acentuación y uso de mayúsculas y minúsculas.

Se señala entre corchetes toda intervención realizada en el texto, con justificación de la misma en nota textual al pie; cuando la causa de la enmienda es una y la misma para todo el documento -por ejemplo, imposibilidad de lectura por pérdida de un tramo del folio en la costura apretada del volumen- sólo se hace advertencia una única vez.

Se utilizan comillas dobles ( «») para las citas textuales idénticas, y comillas simples, (') con indicación de confrontar ( $c f$. ), para valores sémicos aproximados registrados en las fuentes referidas. Cuando se estima necesario, se recoge, junto con el valor sémico de uso puntual del contexto, otro próximo complementario.

Respecto de la memoria - equivalente al concepto coseriano de historia, pues el autor rumano señala que sólo ésta corresponde al ser real de la lengua, pues "sólo la historia puede considerar con coherencia la tensión entre las estructuras diacrónicamente concurrentes ("viejas" y "nuevas") y una misma lengua funcional en devenir" (Coseriu 1992: 31) - debemos considerar que la función última de editar un texto colonial con las particulares características que pueda tener no es sólo de mera erudición, ni de probar una teoría lingüística o modificarla es, en último término, replicar a Jano: evidenciar lo más ampliamente nuestro pasado para que esa experiencia nos permita construir futuro, equilibrando el presente que vivimos. Para estos efectos, desde el punto de vista de la edición, corresponderían los siguientes niveles:

2.7) versión modernizada del texto: cuyo propósito sea "el de dar versiones del contenido que sean fáciles de leer y puedan llegar a un público lo más amplio posible". Esto cumple con las finalidades de rescate de nuestro patrimonio cultural textual y de difusión pública que buscan, hoy en día, los proyectos académicos. Como se señaló, el texto de base es la transcripción paleográfica, por lo que se parte de una versión con un significado concreto, pues debemos hacernos cargo de que, en este caso, no sólo bastaría con regularizar la ortografía y la sintaxis al uso actual de la norma, sino que también se requiere de una comprensión del discurso de fondo y representarlo de una manera adecuada para que no le sea extraño al lector contemporáneo.

Esto quiere decir que, en principio, no sólo se plantea una regularización ortográfica - lo cual no es un simple diseño de acuerdo a los patrones actuales de la ortografía - sino 
que, como se pretende aquí, consistiría en llevar a cabo una 'intervención' en el nivel del sentido, puesto que éste se relaciona con la adecuación, que corresponde al saber lingüístico de este tipo de contenido.

El lector contemporáneo común, particularmente el que conforma el contexto de nuestro sistema escolar público, requiere conocer de primera mano un pasado que ha sido 'demonizado' y que permanentemente vuelve a actualizarse. No por nada hoy seguimos viviendo el llamado "conflicto mapuche"; más de 470 años de olvido en un pueblo que, al parecer, no quiere tener memoria.

Finalmente, la última capa es la

2.8) ilustración: la Conquista espiritual, a diferencia de otros textos de su especie, no contiene imágenes de los religiosos a los cuales hace referencia, ni a situaciones específicas, sino que, tal como lo señalamos, se trata de un texto a doble columna que relata la santidad de la vida de algunos religiosos de la Compañía de Jesús en el Reino de Chile. Lo que se pretende, con este último estudio, es que un ilustrador profesional investigue e interprete cada uno de los textos referidos a un personaje en particular, presente una propuesta al equipo y se lleve a cabo la mejor realización posible, en virtud de criterios históricos y filológicos, con el fin de poner de relieve aspectos fundamentales para la mejor comprensión de este menologio en particular, siendo fieles al espíritu de las obras del XVII, en cuanto a técnica de ilustración y modelo gráfico. Cabe señalar, en todo caso, que esta 'capa' se encuentra relacionada con la versión modernizada del texto que será editado en versión papel, correspondiente a la difusión general del mismo y teniendo como público objetivo a uno no especializado, como por ejemplo, el que accede a través de bibliotecas públicas o a de librerías.

En la presente investigación, el trabajo es realizado por el ilustrador chileno Américo Robles, de quien mostramos algunos de sus trabajos para la obra de Rosales: 
ESTUDIOS FILOLÓGICOS
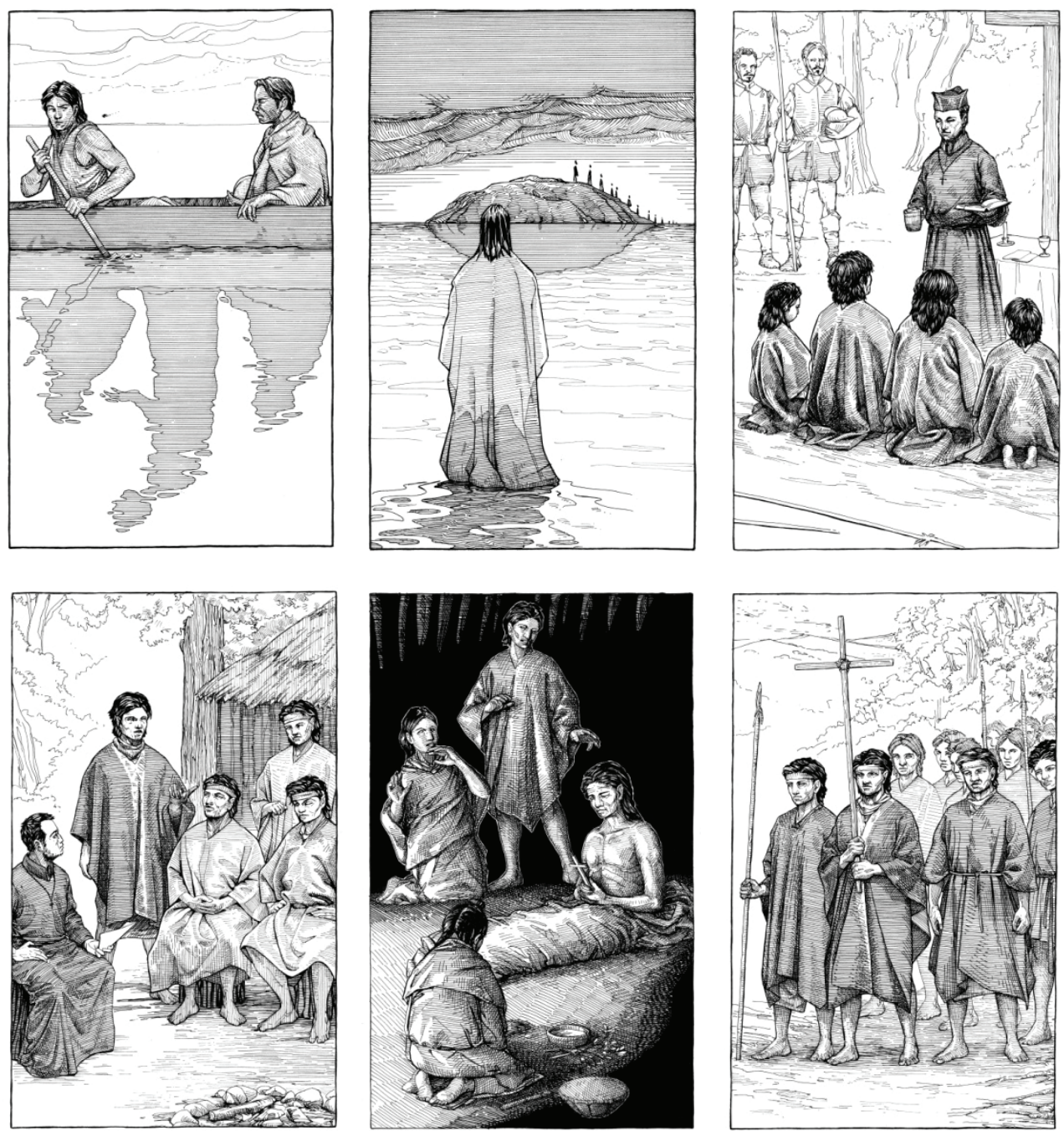


\section{Corolario}

El trabajo de edición de un texto colonial chileno -dadas las particulares características de la zona, en cuanto a periferia del mundo hispanoamericano, como otras más en el Continente- requiere de especial atención, a fin de explicar cabalmente la lengua y cultura de la época, contextualizar los usos que aparecen en el escrito y disminuir al mínimo las posibles alteraciones o adulteraciones del original.

Como bien señala Kordić (2007):

no solo hay que determinar valores sémicos que con frecuencia no están recogidos en diccionarios, sino que hay que comprender exóticas formaciones morfológicas y acertar en la interpretación de un discurso sintácticamente embarullado y a veces desconcertante. Cuando no se tienen los criterios, los métodos y la formación en materia idiomática y textológica, las conclusiones pueden desembocar en magnas (y a veces tendenciosas) confusiones ilustradas. La labor hermenéutica historiográfica debe hermanarse con la filológica.

Para facilitar el trabajo actual y futuro, así como la labor docente en esta disciplina, la edición en papel del menologio de la Conquista espiritual del Reino de Chile incluirá un abecedario paleográfico, las abreviaturas y su respectivo despliegue, así como un estudio previo del conjunto textual que se publica, con especial referencia a los aspectos que puedan parece más oscuros al lector actual, dada su escasa familiaridad con el contexto histórico o con el tipo de lengua que se presenta.

\section{Obras Citadas}

Casassas Canals, Xavier. 2011. "La edición de manuscritos romances aljamiado-árabes: una propuesta de edición por capas”, en https://www.academia.edu/19622044/La_ edici\%C3\%B3n_de_manuscritos_romances_aljamiado-\%C3\%A1rabes_una_propuesta_de_edici\%C3\%B3n_en_capas).

Company, Concepción. 1994. Documentos lingüisticos de la Nueva España (Altiplano Central), México: UNAM, Instituto de Investigaciones Filológicas, Centro de Lingüística Hispánica.

Contreras Seitz, Manuel. 2005. Ilegibilidad y cotidianeidad. Paleografía y colección diplomática de documentos chilenos del periodo colonial (1548-1651), Osorno: Colección Fuentes Documentales, PEDCH, Universidad de Los Lagos.

Contreras Seitz, Manuel. 2013. Memoria documental en textos chilenos del periodo colonial, Vol. I. Edición semidiplomática, siglo XVI. Saarbrücken, Alemania: Editorial Académica Española.

Contreras Seitz, Manuel y Maura Salvo. 2013. Memoria documental en textos chilenos del 
periodo colonial, Vol. II. Edición semidiplomática, siglo XVII. Saarbrücken, Alemania: Editorial Académica Española.

Contreras Seitz, Manuel, Ricardo Molina y Rocío Jara. 2013. Memoria documental en textos chilenos del periodo colonial, Vol. III. Edición semidiplomática, siglo XVIII. Saarbrücken, Alemania: Editorial Académica Española.

Coseriu, Eugenio. 1958. Sincronía, diacronía e historia, Madrid: Gredos.

- - -. 1962. Teoría del lenguaje y lingüistica general, Madrid: Gredos.

Kordić Riquelme, Raïssa. 2005. Testamentos coloniales chilenos, prólogo y edición crítica; estudio preliminar de Cedomil Goić, BACH, vol. 6, Madrid: Universidad de NavarraIberoamericana/Vervuert.

- -. 2010. "Falsas variantes en las ediciones de textos", Boletín de Filología, Tomo XLV, No 2, Santiago: Universidad de Chile, 279-286.

Melis, Chantal, Agustín Rivero y Beatriz Arias. 2008. Documentos Lingüisticos de la Nueva España (Golfo de México), México: UNAM, Instituto de Investigaciones Filológicas, Centro de Lingüística Hispánica.

Real Academia Española. 1993. Documentos para la historia lingüistica de Hispanoamérica. Siglos XVI a XVIII, Anejo LIII BRAE, $\mathrm{M}^{\text {a }}$ Beatriz Fontanella de Weinberg (comp.), ALFAL, Comisión de Estudio Histórico del Español de América, Madrid: EspasaCalpe.

- - - 2000. Documentos para la historia lingüistica de Hispanoamérica. Siglos XVI a XVIII, II, Anejo LVIII BRAE, Elena Rojas Mayer (comp. y ed.), ALFAL, Comisión de Estudio Histórico del Español de América, Madrid: Espasa-Calpe.

- -. 2008a. Documentos para la historia lingüistica de Hispanoamérica. Siglos XVI a XVIII, III, Anejo LX BRAE, Elena Rojas Mayer (comp. y ed.), ALFAL, Comisión de Estudio Histórico del Español de América, Madrid: Espasa-Calpe.

- - . 2008b. Documentos para la historia lingüistica de Hispanoamérica. Siglos XVI a XVIII, IV, Anejo LXI BRAE, Elena Rojas Mayer (comp. y ed.), ALFAL, Comisión de Estudio Histórico del Español de América, Madrid: Espasa-Calpe.

Rivarola, José Luis. 2009. Documentos lingüisticos del Perú. Siglos XVI y XVII. Edición y comentario, Madrid: CSIC. 
